\title{
Diagnosis and Management of 46 XX Disorders of Sex Development (DSD) Aromatase Deficiency in Resource-Restricted Setting
}

\author{
Luh Ayu Asri Wijani*, Muhammad Faizi, Nur Rochmah \\ Department of Child Health, Faculty of Medicine University Airlangga \\ Dr. Soetomo General Academic Hospital, Surabaya, Indonesia
}

*Corresponding author details: Luh Ayu Asri Wijani; ayuasriwijani@gmail.com

\begin{abstract}
A 12 years old children with genital ambiguity was reported. Late diagnosed was occurred due to complexity of the disease. Initial assessment in newborn baby is importance for early diagnosis and prompt treatment for disorder of sex development with genital ambiguity. Experienced multidisciplinary team is required for optimal care children with DSD. Further monitoring and continuous follow up are needed to evaluate response of hormonal replacement therapy, surgical options, potential for fertility, and psychosocial development to improve patient QoL.
\end{abstract}

Keywords: genital ambiguity; disorders of sexual development; ambiguous genitalia

\section{INTRODUCTION}

Disorder of sexual development (DSD) is a rare case, as defined by congenital condition which development of chromosomal, gonadal or anatomic sex is atypical. ${ }^{1}$ This condition can be identified at different times of life, in fetuses or newborns with the chief complaint ambiguous external genitalia, gonadal dysgenesis and internal genitalia that are discordant for the constitution of sexual chromosomes, also can be subsequently diagnosed in individuals with late puberty, unexpected virilization or gynecomastia, infertility or gonadal tumors. ${ }^{2}$

The worldwide incidence of 46,XX DSD, consisting primarily of CAH - mostly 21-hydroxylase deficiency -, has been estimated to be 1 in 14,000-15,000 live births, but it varies by regions because of ethnic differences in gene mutation frequency. A rare cause of $46, \mathrm{XX}$ DSD is Aromatase deficiency (AroD). After the first description of this autosomal recessive disorder back in 1991, a total of about 40 such cases have been reported in the world literature until 2019.3 This is the first case reported from RSUD DR Soetomo.

The challenges facing the genetics of DSD include the development of a diagnostic algorithm that integrates various technologies (including transcriptomics, epigenomics, proteomics and metabolomics), so that the etiology of the entity can be established. Definitive diagnosis is AroD established by CYP19A1 mutation analysis; however, in a resource-restricted setting, the diagnosis can also be achieved with confidence after ruling out other causes of ' $46, \mathrm{XX}$ ' DSD by detailed history, relevant hormonal and appropriate radiological investigations.3 Optimal care for children with DSD requires an experienced multidisciplinary team. Hormonal replacement therapy, surgery, psychological counselling were required to improve quality of life (QoL).

The objective of this case is to report a rare case of a child with 46,XX DSD highly suspicious of Aromatase deficiency, focusing on diagnosis and management.

\section{CASE REPORT}

$\mathrm{N}, 12$ years old child reared as a boy was admitted to pediatric outpatient clinic with chief complain of ambiguous genitalia. Genital ambiguity was noticed at birth. After birth the patient was initially said as female by midwife, but the day after change to male because of the urine was gushing. The patient was born full term by vaginal delivery at private midwife, on June 25 th 2008 . The birth weight was 3400 grams, length $51 \mathrm{cms}$, cried immediately, there was no history of cyanosis and jaundice. Patient mother was given hormonal therapy by obstetrician 1 year before pregnancy for 3 months (she forgot the name of drug), the menstrual cycle was normal. Patient mother had developed a severe form of cystic acne which appeared since first trimester of gestation and resolved spontaneously post-delivery. The mother denied androgenic drug intake during the pregnancy and did not notice voice change, hirsutism, or clitoromegaly.

Since birth patient was raised as a boy until age of 12 years. Patient's mother feel that the patient has small size of penis, and have checked several times to doctor and nurse said it was normal cause by overweight. The patient first time visit to urologist on July 2019 asked for circumcision, the doctor said that there was impalpable testis and the patient need further examination.

The patient already completed all basic immunization (BCG, hepatitis B, DPT, polio, measles) in primary health care. His parents were in healthy condition, with good history of antenatal care by obstetrician. There was no history of smoking parents. Growth and development history revealed appropriate with her friends of the same age. The patient was the only child. There were no relatives with history of endocrine or hormonal disturbance nor abnormal genital.

Physical examination revealed blood pressure 100/60 (systolic BP <50th percentile, diastolic BP < 90th Percentile), heart rate was 88 beats per minute, palpable pulse, with warm extrimities, capillary refill time $<2$ seconds; 
spontaneous respirations 24 times per minute, temperature $36,50 \mathrm{C}$ and saturation was $99 \%$ without 02 support.

There was no dysmorphic face. The chest was symmetric no deformity, and there was no intercostal retraction There was no murmur. The breath sound in both lungs were vesicular, ronchi on both lungs, no stridor, nor wheezing was found. Abdominal examination showed normal skin turgor, no

abdominal enlargement, no dilated veins, with no palpable liver or spleen. No clammy, edema and clubbing finger were presented on extremities. Patient with no rash, no cyanosis, no hyperpigmentation, no lumps or wounds or skin lesion, no discharge from ears, no bleeding or enlargement from lips and no enlarged tonsil or lymph nodes on the throat. There was BCG scar on the upper right arm. The body weight was $59 \mathrm{kgs}\left(90^{\text {th }}-97^{\text {th }}\right.$ percentile), height was $154 \mathrm{cms}\left(50^{\text {th }}-75^{\text {th }}\right.$ percentile). The BMI was 25 $\mathrm{kg}\left(90^{\text {th }}-95^{\text {th }}\right.$ percentile) or overweight.

From local genital examination revealed, impalpable testes, nor hair in pubic area. A Clitoral/gland length crosswise of $13 \mathrm{~mm}$ without palpable gonads. There was almost complete labioscrotal fusion with scrotal rugosities and a single perineal opening consistent with Prader stage III genitalia.
From history taking, physical examination, radiology, laboratory and hormonal result we had a working diagnosis of 46 XX DSD.

At first the patient came to Urologist asking for circumcision. By the doctor, due to impalpable testis the patient asked for ultrasonography examination, and the result was, no sign of both testis on inguinal or scrotum. Then the patient referred to gynecologist and underwent abdominal laparoscopic and revealed Uterus, normal size ovary and fallopian tube. The patient offered to have a chromosome analysis with the result was $46 \mathrm{XX}$. From the laboratory result revealed $\mathrm{Hb} 14.5 \mathrm{~g} / \mathrm{dL}$, leucocyte 8910 /dL, Thrombocyte 373000 /dL, BUN 8 mg/dL, Creatinine serum $0,4 \mathrm{mg} / \mathrm{dL}$, potassium $3.6 \mathrm{mEq} / \mathrm{dL}$, sodium 140 $\mathrm{mEq} / \mathrm{L}$. Than the patient referred to endocrinology outpatient clinic RSUD DR Soetomo.

The patient underwent hormonal examination revealed 17-OH progesterone $0.6 \mathrm{ng} / \mathrm{mL}( \pm 1.69)$, LH $27 \mathrm{mlU} / \mathrm{mL}$ $(<0.1-7.8)$, FSH $50.95 \mathrm{mlU} / \mathrm{mL}(0.57-6.89)$,

testosterone $6.89 \mathrm{ng} / \mathrm{dL}(3-68)$, estradiol $<5 \mathrm{pg} / \mathrm{mL}(<5$ 20.0). From genitography examination found two different tracts (vagina and urethra) without filling defect and contrast leakage. USG examination showed normal size uterus $4 \mathrm{cms}$ with cervix $3 \mathrm{~cm}$ and left and right ovary, testis was not found.

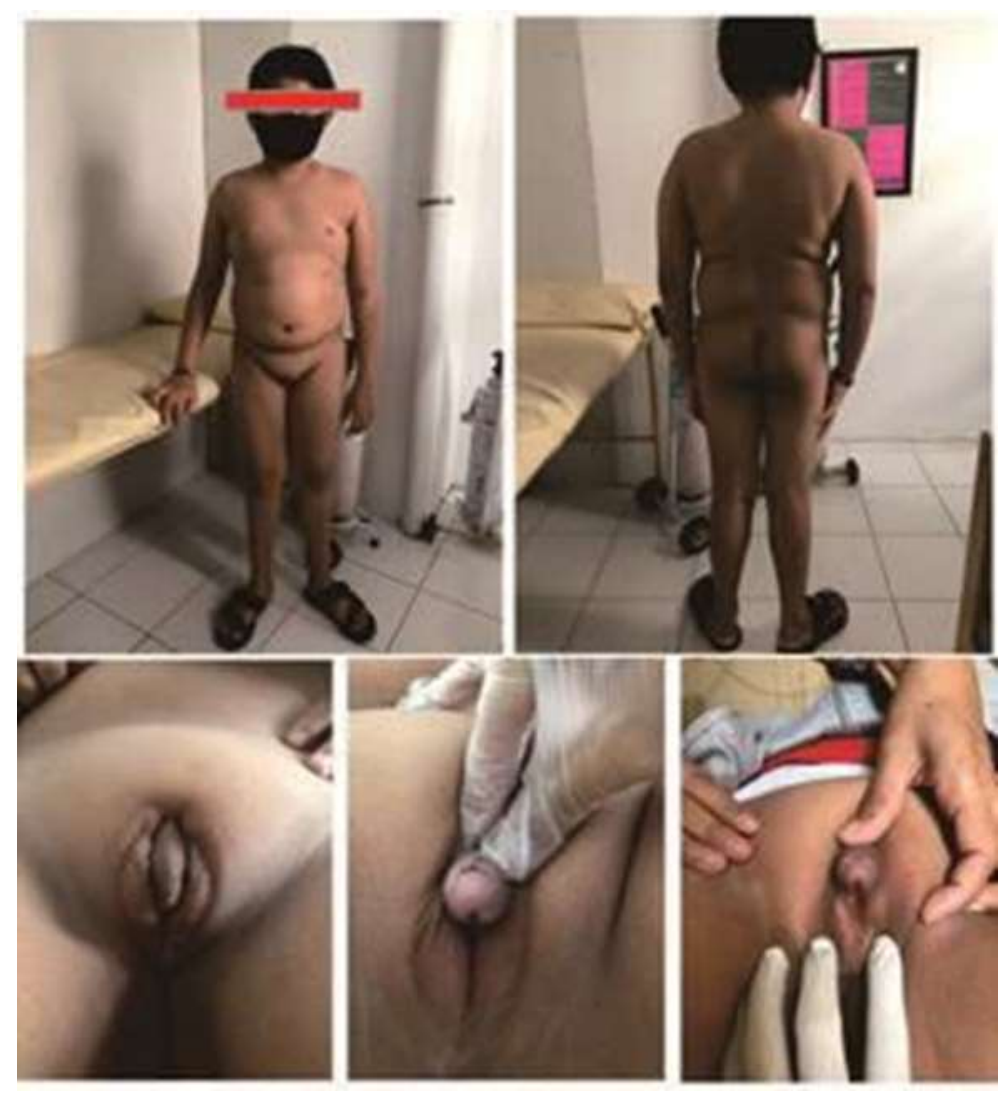

FIGURE 1: Picture of the patient 12 years old with Genital 


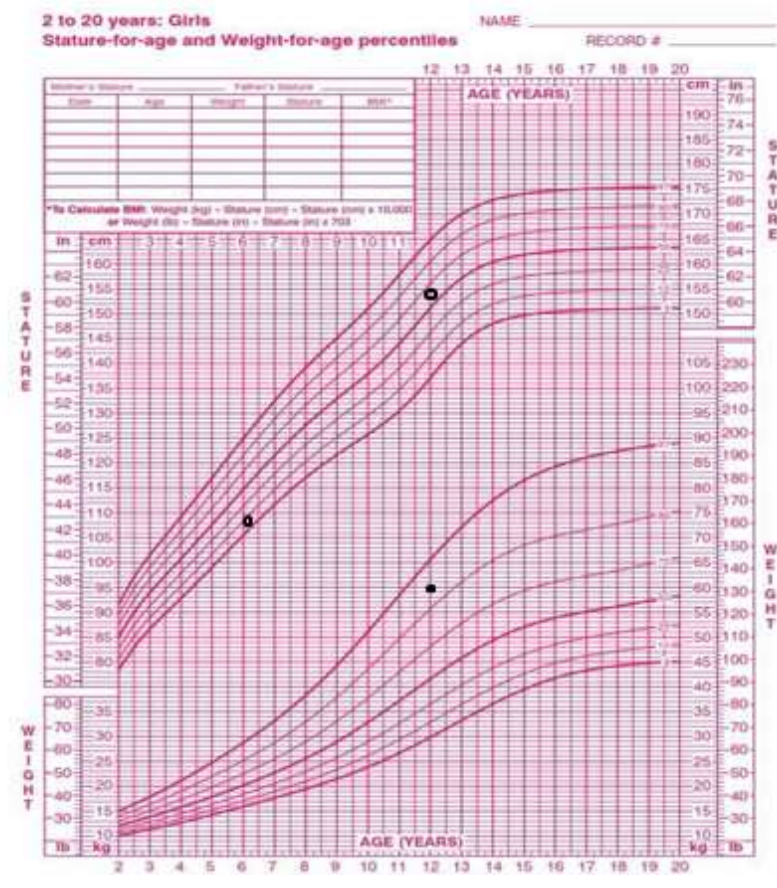

(a)

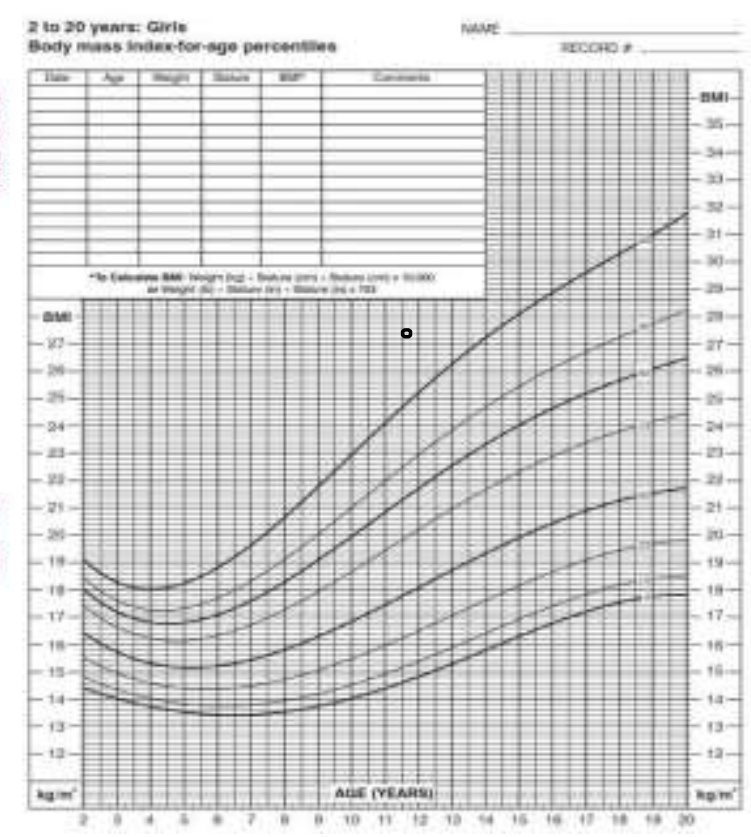

(b)

FIGURE 2: CDC Growth Chart 2000 (a) stature for age and weight for age and (b) BMI for age percentiles for a 12 year girl Source: Developed by the national center for health statistics in collaboration with the national center for chronic disease prevention and health promotion, 2000. https://www.cdc.gov/growthcharts

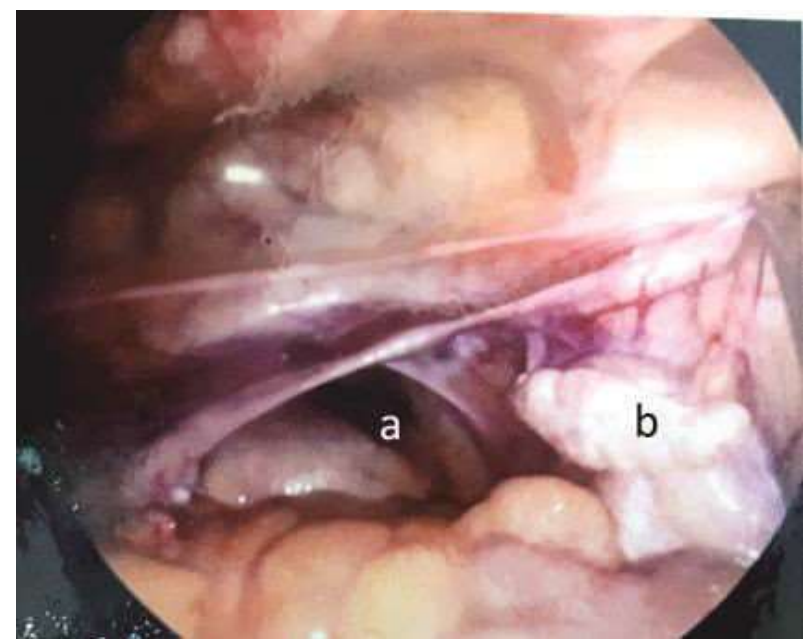

FIGURE 3: Laparoscopic result: (a) Uterus, (b) Ovary

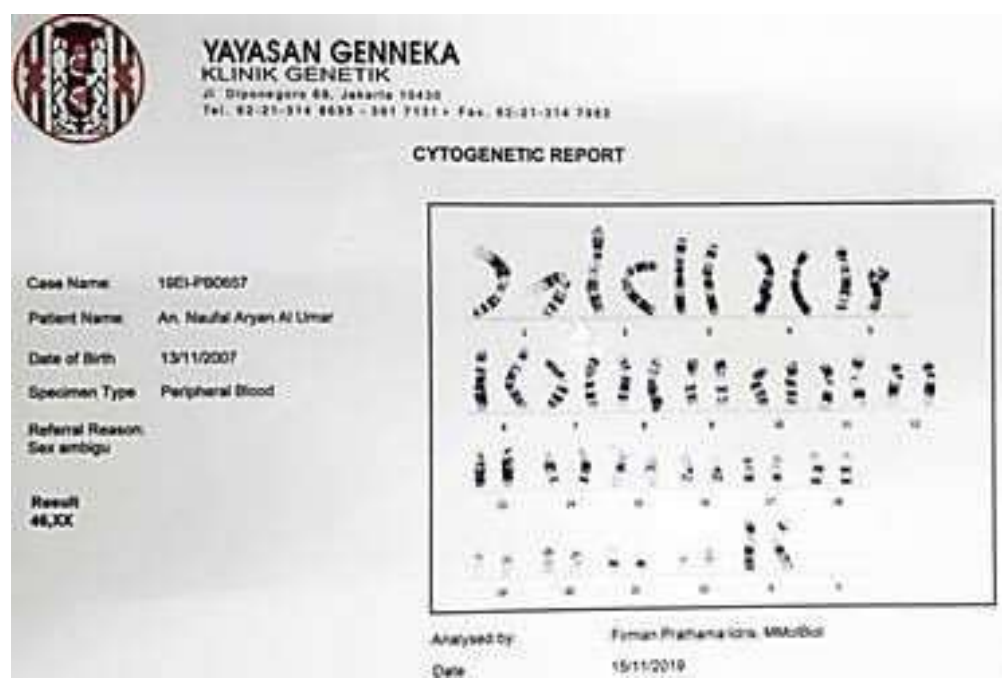

FIGURE 4: Chromosome analysis result on November $15^{\text {th }} 2019$ 
Then the patient gives HCG stimulation test for 6 weeks and after that the hormonal laboratory result were testosterone $16.27 \mathrm{ng} / \mathrm{dL}$ (3-68), estradiol $<5 \mathrm{pg} / \mathrm{mL}(<5-20.0)$ on 25th February 2020 and testosterone $32.27 \mathrm{ng} / \mathrm{dL}$ (3-68), estradiol $<5 \mathrm{pg} / \mathrm{mL}(<5-20.0)$ on $2^{\text {nd }}$ April 2020.

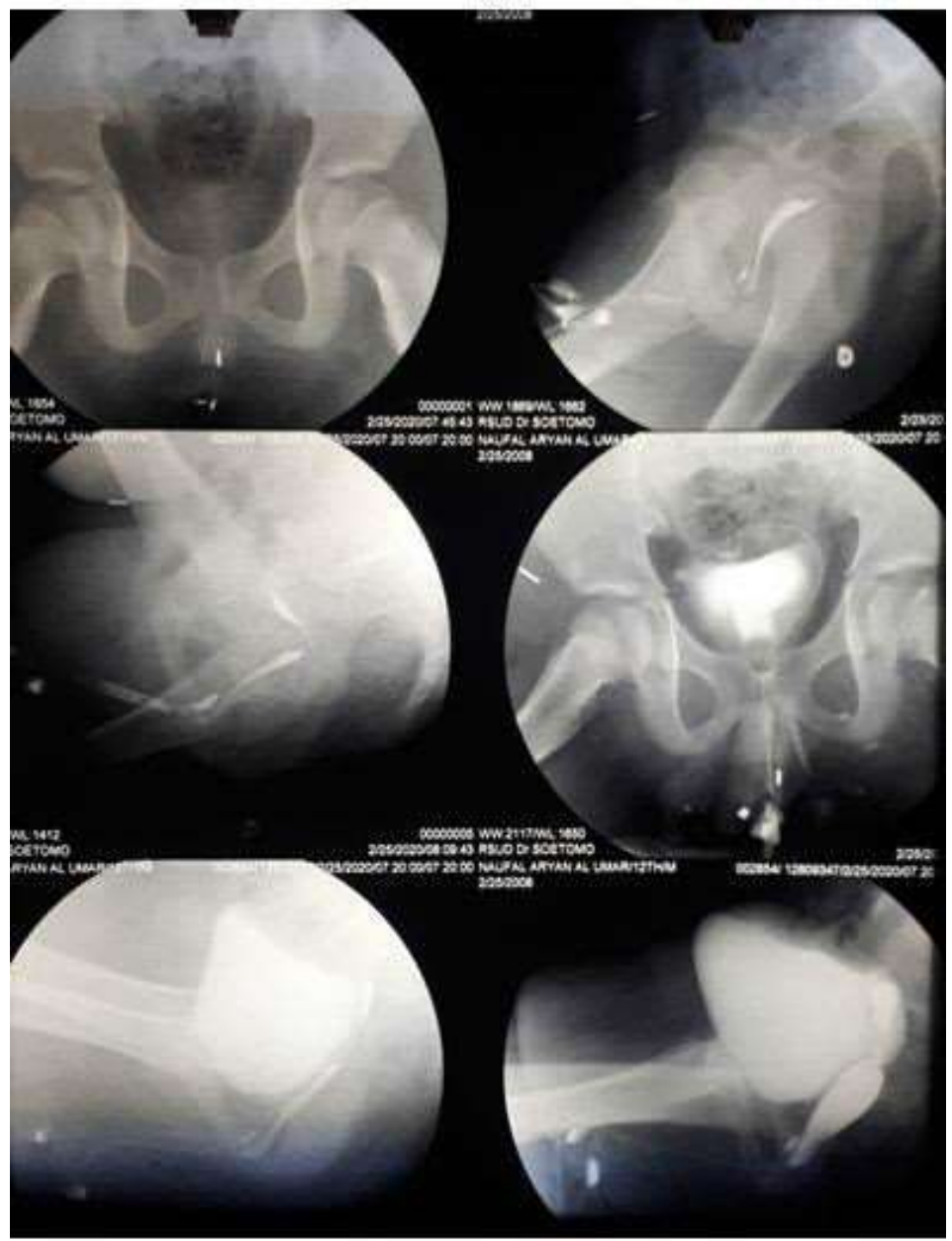

FIGURE 5: Genitography on February 25th 2020

From history taking, physical examination, radiology, laboratory and hormonal result Our final diagnosis was highly suspected 46XX DSD due to aromatase deficiency.

After multidiscipline discussion with the patient and family, the patient and family decided to choose the female gender. Now the patient ongoing hormonal replacement therapy with estradiol $0.5 \mathrm{mg}$ once daily alternate day. The patient also referred to Psychiatry department for psychological counselling. She also consulted to urology department and planned for reconstructive surgery.

\section{DISCUSSION}

\section{Diagnosis}

Disorders of sexual development (DSD) were defined in the Chicago Consensus, 2006 as congenital conditions in which the development of chromosomal, gonadal and anatomical sex is atypical (consensus 2006). Criteria that suggest DSD include (1) overt genital ambiguity (eg, cloacal exstrophy), (2) apparent female genitalia with an enlarged clitoris, posterior labial fusion, or an inguinal/labial mass, (3) apparent male genitalia with bilateral undescended testes, micropenis, isolated perineal hypospadias, or mild hypospadias with undescended testis, (4) a family history of DSD such as CAIS, and (5) a discordance between genital appearance and a prenatal karyotype. Most causes of DSD are recognized in the neonatal period; later presentations in older children and young adults include: (1) previously unrecognized genital ambiguity; (2) inguinal hernia in a female; (3) delayed or incomplete puberty; (4) virilization in a female; (5) primary amenorrhea; (6) breast development in a male; and (7) gross and occasionally cyclic hematuria in a male. 1,4
The clinical evaluation of an individual with DSD or atypical genitalia begins with evaluation of vital signs, general physical examination, description of sexual characteristics and detailed evaluation of the perineal area consisting of observation, palpation and measurement, to be described according to Prader's classification plus a complete clinical history including prenatal and family history in a multidisciplinary group assessment (endocrinologist, urologist, geneticist, gynecologist, pediatrician, psychologist) to achieve an accurate diagnosis. ${ }^{5}$

First-line tests include measurement of 17-hydroxyprogesterone, blood electrolytes, determination of AMH and gonadotropin levels, together with a cytogenetic study (karyotype) and an abdominal ultrasound in search of Müllerian structures. Additional tests will be dependent on the results of the initial tests to guide the diagnostic suspicion. ${ }^{6}$

In this case, a 12 years old child presented with disorder of sex development, have done karyotyping examination with result was 46,XX (46,XX DSD). Patient with 46,XX DSD can cause by disorder of ovarian development, or fetal androgen excess including $\mathrm{CAH}$ and non $\mathrm{CAH}$. The most common condition that presents to

46,XX karyotype and DSD is congenital adrenal hyperplasia (CAH) due to severe or complete 21hydroxylase deficiency (21-OHD). Although rarer, other monogenic defects in steroidogenesis may cause androgen excess and determine similar phenotypic conditions that are related to adrenal and/or gonadal dysfunction. 
Gönül Öcal, et al reported Types and ratios of each presentation of our 95 patients with 46,XX DSD were as follows: 82 had androgen excess (86.3\%): (74 had classical congenital adrenal hyperplasia, 2 had $\mathrm{CAH}$ variant possibility of P450-oxidoreductase gene defect), 6 had disorders of ovarian development (6.3\%): (1 patient had gonadal dysgenesis with virilization at birth with bilateral streak gonad, 4 patients had complete gonadal dysgenesis, and 1 patient had ovotesticular DSD) and 7 had other 46,XX DSD. ${ }^{7}$ Walia et al, reported of the 74 patients with $46, \mathrm{XX}$ DSD, $52(70.27 \%)$ had congenital adrenal hyperplasia $(\mathrm{CAH})$ and eight $(10.8 \%)$ had ovotesticular DSD. Five patients with sex chromosome DSD had mixed gonadal dysgenesis. ${ }^{8}$

TABLE 1: Classification of DSD

\begin{tabular}{|c|c|c|c|c|c|}
\hline \multirow{3}{*}{$\begin{array}{c}\text { Sex } \\
\text { Chromosome } \\
\text { DSD }\end{array}$} & \multicolumn{2}{|c|}{ 46,XY DSD } & \multicolumn{3}{|c|}{ 46,XX DSD } \\
\hline & \multirow{2}{*}{$\begin{array}{c}\text { Disorder of } \\
\text { testicular } \\
\text { development }\end{array}$} & \multirow{2}{*}{$\begin{array}{c}\text { Disorder of } \\
\text { androgen } \\
\text { synthesis/action }\end{array}$} & \multirow{2}{*}{$\begin{array}{c}\text { Disorder of } \\
\text { ovarian } \\
\text { development }\end{array}$} & \multicolumn{2}{|c|}{ Fetal androgen excess } \\
\hline & & & & CAH & Non CAH \\
\hline \multirow{12}{*}{$\begin{array}{l}\text { - 45,X Turner } \\
\text { and Variants } \\
\text { - } 47, \mathrm{XXY} \\
\text { - Klinefelter and } \\
\text { Variants } \\
\text { - 45,X/46XY } \\
\text { MGD } \\
\text { - Chromosomal } \\
\text { Ovotesticular } \\
\text { DSD }\end{array}$} & - Complete & - Androgen & - Ovotesticular & - 21-OH & - Aromatase \\
\hline & $\begin{array}{l}\text { Gonadal } \\
\text { Dysgenesis }\end{array}$ & Synthesis Defect & DSD & - Deficiency & Deficiency \\
\hline & & - LH-Receptor & - Testicular & - 11-OH & - POR Gene \\
\hline & $\begin{array}{l}\bullet \text { Partial } \\
\text { Gonadal }\end{array}$ & Defect & DSD (e.g. & - Deficiency & Defect \\
\hline & Dysgenesis & - Androgen & $\begin{array}{l}\text { SRY+, dup } \\
\text { SOX9) }\end{array}$ & & - Maternal \\
\hline & - Gonadal & Insentivity & & & Luteoma \\
\hline & Regression & - $5 \alpha$-Reductase & $\begin{array}{l}- \text { Gonadal } \\
\text { Dysgenesis }\end{array}$ & & - Iatrogenic \\
\hline & - Ovotesticular & Deficiency & & & \\
\hline & DSD & - Disorders AMH & & & \\
\hline & & - Timing Defect & & & \\
\hline & & $\begin{array}{l}\text { - Endocrine } \\
\text { Disrupters }\end{array}$ & & & \\
\hline & & - Cloacal Extrophy & & & \\
\hline
\end{tabular}

Source: Öçal G. (2011). Current concepts in disorders of sexual development. Journal of clinical research in pediatric endocrinology, $3(3), 105-114 .^{9}$

Approximately $75 \%$ of patients who present in the emergency room with ambiguous genitalia with hyponatremia and hyperkalemia and a lack of palpable testes have a diagnosis consistent with CAH. Douglas et al recommend that the standard workup for CAH include the following: electrolytes, glucose, 170HP, plasma renin, D4 androstenedione, testosterone, 11deoxycortisol, and DHEA (weak recommendation, very low-quality evidence). ${ }^{10}$ In this case, the patient was reared as a boy, the parent complain small size of penis and came to urologist for circumcision.
Physical examination revealed no hypertension, no sign of dehydration. From genital examination revealed impalpable testes, no pubic hair, almost complete labioscrotal fusion with scrotal rugosities and a single perineal opening consistent with Prader stage III genitalia. From laboratory examination revealed normal electrolyte and blood glucose. Hormonal examination found normal 17-0H progesterone $0.6 \mathrm{ng} / \mathrm{mL}( \pm 1.69)$. USG examination showed no testes, normal size uterus with cervix and left and right ovary. According to the data we can exclude CAH from this patient.

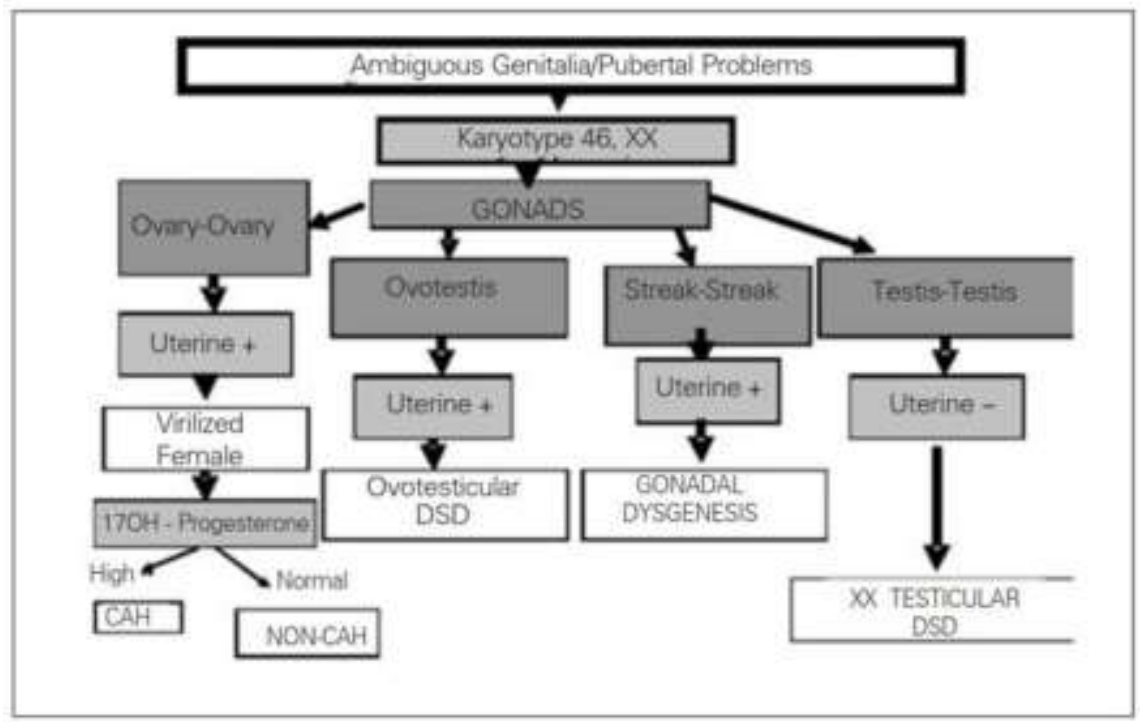

FIGURE 6: Diagnostic algorithm of 46,XX DSD for new classification

DSD: disorders of sexual development, CAH: congenital adrenal hyperplasia

Source: Öçal G. (2011). Current concepts in disorders of sexual development. Journal of clinical research in pediatric endocrinology, 3(3), 105-114. ${ }^{9}$ 
Patient mother was given hormonal therapy by obstetrician 1 year before pregnancy for 3 months (she forgot the name of drug), the menstrual cycle was normal. Patient mother had developed a severe form of cystic acne which appeared since first trimester of gestation and resolved spontaneously post-delivery. Laboratory result of hormone was LH $\uparrow 27 \mathrm{mlU} / \mathrm{mL}(<0.1-7.8), \mathrm{FSH} \uparrow 50.95$ $\mathrm{mlU} / \mathrm{mL}$ (0.57-6.89), testosterone $6.89 \mathrm{ng} / \mathrm{dL}$ (3-68), estradiol $\downarrow<5 \mathrm{pg} / \mathrm{mL}(<5-20.0)$. Then the patient gives HCG stimulation test for 6 weeks and after that the

hormonal laboratory result was testosterone $16.27 \mathrm{ng} / \mathrm{dL}$ (3-68), estradiol $<5 \mathrm{pg} / \mathrm{mL}(<5-20.0)$ on 5 th day and testosterone $32.27 \mathrm{ng} / \mathrm{dL}$ (3-68), estradiol $<5 \mathrm{pg} / \mathrm{mL}(<5$ 20.0 ) on 20 th day.

In this case, patient showed response to hCG stimulation test. It was altered to be defined as a testosterone greater than upper pubertal limit, or testosterone increment greater than twice the baseline value. ${ }^{11}$ (HCG test Lucas, 2020) Stimulation with hCG allows the identification of functioning testicular tissue as well as biosynthetic defects in testosterone. ${ }^{12}$ Grant et al, suggest that a post-HCG testosterone level below $2.0 \mathrm{nmol} / \mathrm{l}$ (58 ng/dL) may indicate impaired Leydig-cell function, particularly if there is only a small rise in testosterone after stimulation. However, we still have to wait until many of the subjects reach the age of puberty in order to evaluate our results fully. ${ }^{13}$
Other cause 46,XX DSD with ovary-ovary gonad and normal $17-\mathrm{OH}$ progesterone level are aromatase deficiency, maternal androgen excess due to tumor or drug, and iatrogenic. The most common cause of maternal virilization during pregnancy is a luteoma, a benign hyperplastic ovarian growth of luteinized stroma, granulose or theca cells. About $25 \%$ of Luteoma will secrete androgens and fewer than half of affected mothers will have signs of hyperandrogenism. Only about half of the girls born to symptomatic mothers will show some signs of virilization. ${ }^{14}$ There was no history of tumor and drug during pregnancy, so we can exclude this cause.

Aromatase deficiency (AroD) is a rare genetic condition, autosomal recessive disorder that is caused by mutations in the CYP19A1 gene, which is located on chromosome 15q21.1. Aromatase enzyme converts androgens into estrogens in many tissues. AroD causes atypical genitalia in $46, \mathrm{XX}$ fetuses and maternal virilization during pregnancy due to an increased concentration of androgens. Ovaries are usually large and polycystic in girls with AroD.15,16 The combination of maternal virilization, in-utero virilization, and features of estrogen deficiency (pubertal delay, tall stature, cystic ovaries) along with androgen excess (hirsutism) during adolescence, strongly suggested aromatase deficiency.

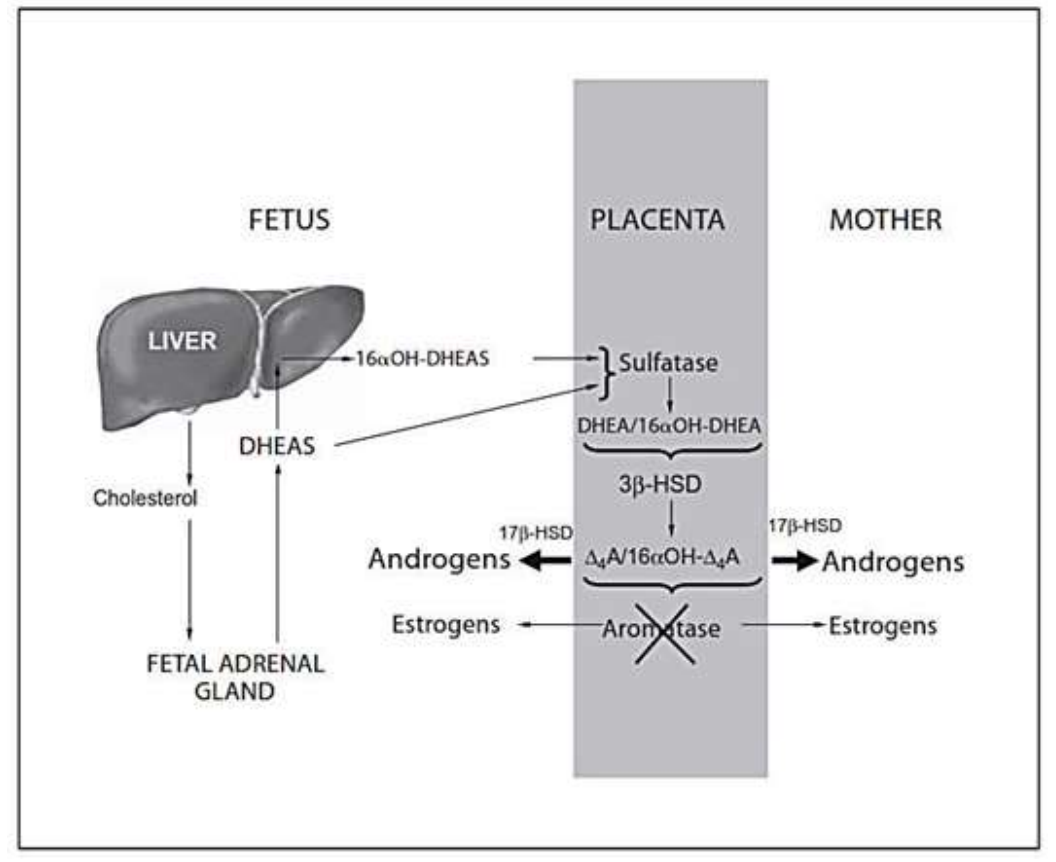

FIGURE 7: Compartmentalization of sex hormone metabolism in the fetoplacental unit.

Source: Belgorosky, A., Guercio, G., Pepe, C., Saraco, N., \& Rivarola, M. A. (2009). Genetic and clinical spectrum of aromatase deficiency in infancy, childhood and adolescence. Hormone research, 72(6), 321-330. https://doi.org/10.1159/00024915916

Verma in 2012 described the clinical course of an Indian girl with aromatase deficiency from birth to 16 years of age. Estrogen replacement was begun at age 13.5 years. The child presented with obesity, tall stature, delayed bone age, osteoporosis, hyperinsulinemia with acanthosis nigricans, and hypergonadotropic hypogonadism with cystic ovaries. Estrogen replacement resulted in a plateauing of height, improvement of bone maturation, and pubertal progression with the disappearance of ovarian cysts. However, hyperinsulinemia and acanthosis nigricans persisted despite estrogen replacement and metformin.
Genetic analysis revealed a homozygous arginine to cysteine substitution at codon 435 in exon 10 of CYP19A1.17 Agrawal, et al 2019 reported 2 case 46,XX DSD aromatase deficiency who diagnosed at pre pubertal state, in both case AroD diagnosed by ruled out any other possibility.

Diagnosing AroD before puberty without genetic analysis in resource restricted setting is difficult. Serial hormonal levels of both infant and mother would give a strong clue and may be sufficient to make the diagnosis. Progressive decline in androgen levels in both mother and child from birth to early infancy are helpful indicators of AD. ${ }^{3}$ 
TABLE 2: Clinical Features and laboratory findings of Aromatase Deficiency

Clinical Features and laboratory

Fetal life:

Genitalia at birth:

Childhood; Puberty:

Adult:

Mother (pregnant woman):

\author{
Infancy/Early Childhood (girls): \\ Puberty (girls):
}

Puberty (girls):
Further enlargement of clitoris Enlarged cystic ovaries

\section{Female with AroD}

Masculinization of the mother during pregnancy Severe clitoromegaly and posterior labioscrotal fusion

Multi-cystic ovaries Absent growth spurt Absent breast development Primary amenorrhea

Normal development of pubic and axillary hair Severe estrogen deficiency Virilization, enlarged cystic ovaries Continued linear bone growth

Severely low maternal serum estradiol and estriol Remarkably elevated maternal serum testosterone, Elevated FSH and undetectable serum estradiol

Multi-cystic ovaries (ultrasound), Retarded bone age

Markedly elevated FSH and LH, Mildly elevated levels of testosterone and androstenedione

Source: Bulun S. E. (2014). Aromatase and estrogen receptor $\alpha$ deficiency. Fertility and sterility, 101(2), 323-329. https://doi.org/10.1016/j.fertnstert.2013.12.02218

In this case the patient was late diagnosed DSD at 12 years of age. The first assessment of a neonate with a suspected DSD can be challenging. In many cases, the genital ambiguity is obvious. However, mild forms of DSD might present with less severe clinical manifestations that challenge the decision to regard the patient as having a DSD. An apparently female newborn with clitoromegaly and posterior labial fusion or an inguinal hernia requires assessment for DSDs. Male newborn should be investigated if bilateral cryptorchidism, hypospadias associated with micropenis, or isolated micropenis is present. Besides those whose genitalia are truly ambiguous, in the clinical situation, infants can often be divided into those who are apparently a boy with atypical genitalia and those who are apparently a girl with atypical genitalia. However, it is very important to bear in mind that the same girl with congenital adrenal hyperplasia may present as an apparent girl with clitoromegaly or an apparent boy with bilateral undescended testes.

When evaluating these infants, the clinical features of the external genitalia that require examination include the presence of gonads in the labioscrotal folds, the fusion of the labioscrotal folds, the size of the phallus and the site of the urinary meatus on the phallus, although the real site of the urinary meatus may, sometimes, only become clear on surgical exploration. These external features can be individually scored to provide an aggregate score, the external masculinization score (EMS). Routine systematic examination of 423 consecutive, apparently healthy, term newborn boys revealed that $412(98 \%)$ had the maximum EMS of 12, 10 had an EMS of 11 and only 1 of 423 had an EMS of less than 11 . The examination of the phallus should note the size and the location of the urethra. In male patients, stretched penile length is reportedly a more reliable measure than flaccid penile length. Stretched penile length is measured from the base of the penis under the pubic symphysis to the tip of the glans with the penis gently stretched. If the fat pad is present, depression is required so that the ruler touches the pubic symphysis to avoid taking a false measurement. The average stretched penile length of a full-term newborn baby is $3.5( \pm 0.7) \mathrm{cm}$. For the assessment of a preterm neonate, the typical penile length can be calculated using the formula $-2 \cdot 27+(0 \cdot 16 \times$ weeks of gestation).
From several algorithm suggest palpable gonad was simple and importance to evaluate in newborn.1,10,12,19

\section{Management}

Optimal clinical management of individuals with DSD should comprise the following: (1) gender assignment must be avoided before expert evaluation in newborns; (2) evaluation and long-term management must be performed at a center with an experienced multidisciplinary team; (3) all individuals should receive a gender assignment; (4) open communication with patients and families is essential, and participation in decision-making is encouraged; and (5) patient and family concerns should be respected and addressed in strict confidence Optimal care for children with DSD requires an experienced multidisciplinary team that is generally found in tertiary care centers. Ideally, the team includes pediatric subspecialists in endocrinology, surgery, and/or urology, psychology/psychiatry, gynecology, genetics, neonatology, and, if available, social work, nursing, and medical ethics. ${ }^{1}$

The patient was reared as a boy, but after multidiscipline discussion, with consider the patient condition 46,XX DSD with genital ambiguity Prader's scale III, impalpable and no testis found with USG and normal hypo functional Müllerian structure, the parents decide to reassignment patient gender to female. Expediting gender assessment and decision is required. Factors that influence gender assignment include diagnosis, genital appearance, surgical options, need for lifelong replacement therapy, potential for fertility, views of the family, and, sometimes, circumstances relating to cultural practices. The 2006 DSD Consensus statement states that all newborn should receive a gender assignment with the decision being informed by expert evaluation by an interdisciplinary team working. Psychosexual outcomes in DSD have been most extensively studied in $46, \mathrm{XX}$ CAH. These studies show that the vast majority of those raised as girls develop and maintain a gender identity as girls/women across the lifespan. However, a less strong female identification, some gender discomfort, and even gender dysphoria occur more often in this group than in women without CAH.20 More than $90 \%$ of patients with $46, \mathrm{XX}$ CAH assigned female in infancy, identify as females. 
Evidence supports the current recommendation to raise markedly virilized 46,XX infants with $\mathrm{CAH}$ as female. Previous case of 46,XX DSD AroD were female and did not change the gender.1,3,17

Psychosexual development is traditionally conceptualized as 3 components:

(1) "gender identity" refers to a person's selfrepresentation as male or female (with the caveat that some individuals may not identify exclusively with either)

(2) "gender role" (sex-typical behaviors) describes the psychological characteristics that are sexually dimorphic within the general population, such as toy preferences and physical aggression

(3) "sexual orientation" refers to the direction(s) of erotic interest (heterosexual, bisexual, homosexual) and includes behavior, fantasies, and attractions. Psychosexual development is influenced by multiple factors such as exposure to androgens, sex chromosome genes, and brain structure, as well as social circumstance and family dynamics. ${ }^{1}$

A newborn does not immediately have self-awareness of his or her sex and gender. Such self-awareness evolves gradually during infancy and childhood. In the absence of discordance between aspects of sex and gender, few will reflect on their gender identity or gender role. Developmental psychology theories have attempted to account for the process of gender development, emphasizing the influences of cognitive and affective learning in interaction with parents, peers, and other aspects of the social environment. Gender role refers to the pattern of masculine or feminine behavior and interests of the person that is conditioned by culture and upbringing. Long before children make consistent and systematic use of genital information as a criterion for sex classification, they have knowledge about gender stereotypes and display gender-role behavior characterized as either feminine or masculine. Adults and peers influence gender development directly by reinforcing or discouraging gender-role behaviors and indirectly by serving as role models. ${ }^{20}$

Kreukels, et al 2018 said that gender reassignment pre pubertal were more gender dysphoric, lower self-esteem and more anxiety and depression. This large study confirms compared with the general population the number of gender changes in people with certain types of DSD is increased but for most diagnoses not very high. However, this does not imply that gender feelings are always entirely unproblematic. Even people who do not want to transition might be uncertain or have questions about their gender and find it difficult to discuss these feelings with their clinician. Because gender issues can be a delicate topic, it might be necessary to approach patients in a sensitive way if one suspects problems in this area. In doing so, it is important to realize that not all patients identify as male or female and want to live in typical male or female social roles. ${ }^{21}$

Gender Dysphoria (GD), according to DSM-5 criteria, is a condition characterized by a marked incongruence between one's experienced/expressed gender and the assigned one, associated with clinically significant distress or impairment in social, occupational, or other important areas of functioning. Recent studies suggest that could hypothetically be considered as a DSD limited to the central nervous system, without the involvement of the reproductive tract.
Children may express a dislike of their sex characteristics and a desire for the characteristics of the experienced gender. Cross-dressing, cross-gender roles in plays, preference for toys and activities of the other gender, friends of the opposite gender, and rejection of cultural gender roles are all commonly reported and currently used as diagnostic criteria for GD. Difficulties in childhood often arise from social intolerance and resultant poor social relations with peers, as well as negative psychological outcome in children with GD. a psychological counselling focused on gender identity and GD in CAH children and adolescents and in their families is recommended. In addition, counselling should include also QoL issues, considering the poorer health-related QoL recently observed in these patients. ${ }^{22,23}$

In this case, due to low estrogen level, and the patient was decided female gender and the patient is on pubertal age, so she was given estradiol $0.5 \mathrm{mg}$ alternate dose and plan for evaluation of hormone after 3 months. To date, information on the effect of estrogen administration to prevent the consequences of estrogen insufficiency is limited and ambiguous. There is no consensus on the appropriate dosage of estrogen replacement therapy and on the usefulness of starting low-dose estrogen treatment from infancy and childhood in affected patients.

In aromatase-deficient girls, estrogen replacement is directed towards maintaining the bone mineral density and preventing formation of ovarian cysts during early childhood, and later, inducing growth spurt, breast development and periods at the expected time of puberty. Thus, continuous estrogen replacement immediately after infancy should be administered judiciously, and bone age and signs of premature breast development should be monitored very closely. Estrogen replacement may be started as early as at 2 years of age using the lowest possible estrogen dose that will prevent formation of ovarian cysts but not cause premature breast development or accelerated bone age. Oral conjugated estrogens $(0.15 \mathrm{mg} /$ day, or every other day) or micronized estradiol $(0.25 \mathrm{mg} /$ day, or every other day) may be used, and the dose may be titrated to maintain the suppression of FSH and LH. The dose of conjugated estrogens should be raised to $0.3 \mathrm{mg} /$ day at the chronological age of 10-12 (or bone age of 11) to initiate secondary sexual characteristics. The goals at this stage of replacement are to initiate breast development and growth spurt. After a year of treatment, the dose of conjugated estrogens may be gradually increased over the next 2 years to 0.625 to $1.25 \mathrm{mg}$ daily depending on the response to treatment. From the second year on, a progestin, e.g., medroxyprogesterone acetate, 5 to $10 \mathrm{mg} /$ day, should be given during the first 10 days of each month to imitate menses and prevent endometrial hyperplasia. By age 14, all aromatase-deficient girls may be switched to a combination oral contraceptive containing 20-35 $\mu$ g of ethinyl estradiol for adequate pituitary suppression and estrogen replacement. ${ }^{18}$

Therapeutic follow-up data are available in 10 reported female patients who had been treated with estrogen at different ages in prepuberty and puberty. In most cases, the treatment was performed in premenarcheal girls aged from 9.6 to 14 years to induce puberty. Generally, increasing doses of oral-conjugated estrogen have been used according to clinical signs of estrogen response, and progestogens were added to induce menarche. This therapeutic model, however, proved to be inadequate in about half of the cases to improve bone maturation delay, suppress elevated gonadotropin levels, regress ovarian cysts, and induce menarche. In the Janner et al. study, a girl with complete AroD started low-dose estrogen therapy at the age of 3.5 years and continued the treatment until the age of 15 years with increasing doses. 
The authors suggested that a low dose of estrogen (E2) (50$100 \mathrm{mg} /$ day), even if insufficient to suppress gonadotropin feedback, is required for normal longitudinal growth and bone age maturation during early childhood, while higher E2 doses (1.4-2 mg/day) are needed more for successful negative feedback on the pituitary-ovarian axis, ovarian cyst regression, breast development, and endometrial reflex than for the normalization of growth and the appearance of menarche in late prepuberty and puberty. ${ }^{15}$

Verma, et al reported 46,XX DSD girl with AroD got estrogen replacement started at $0.3 \mathrm{mg}$ of oral conjugated estrogen every alternate day and increased to once daily after 6 weeks. After the onset of menstrual bleeding six months later, she was shifted to a combined oral contraceptive containing $30 \mu \mathrm{g}$ of ethinyl estradiol. Her hormonal profile and ovarian size were monitored every 6 months.

Information about the course of the disease in adulthood and the long-term consequence for fertility remains unknown. However, the clinical, hormonal, and therapeutic problems that are observed in most patients, along with the surgical consequences of genital reconstruction, might affect reproductive capacity.

In this case found clitoromegaly, with normal urogenital sinus, and was planned for feminization reconstructive surgery. Based on these data, clitoromegaly is diagnosed when the crosswise width of the glans is $>5 \mathrm{~mm}$ between $0-3$ years, $>6 \mathrm{~mm}$ between $4-8$ years, $>5 \mathrm{~mm}$ between $9-$ 12 years, and $>8 \mathrm{~mm}$ between $13-16$ years; when its lengthwise width is $>5-6 \mathrm{~mm}$; and when the length of the hood is $>12.6 \mathrm{~mm}$ between $0-3$ years, $>18.8 \mathrm{~mm}$ between $4-8$ years, $>24.2 \mathrm{~mm}$ between $9-12$ years, and $>27.4 \mathrm{~mm}$ between 13-16 years.24 Feminization surgery, commonly known as feminizing genitoplasty, consists of clitoroplasty, vaginoplasty and labioplasty. These procedures may be done individual, or together in one combined procedure. If the urogenital sinus is closed without concomitant creation of a vagina, this mucosa may not be available for use later. Similarly, if infant clitoroplasty is performed and vaginoplasty is not done at the same time, the clitoral foreskin is lost. The clitoral foreskin is a key component of an inversion vaginoplasty.

However, the vagina is nonfunctional in childhood and delaying vaginoplasty allows the child to be involved not only in the decision-making process but also the pre and post-operative care. This is especially important as vaginal dilation is necessary postoperatively and cannot be done without the willing participation of the child. Further follow-up is needed to elucidate long-term cosmetic and functional results as well as sexual satisfaction of feminizing genitoplasty. ${ }^{25}$

Discussions as to timing of feminizing genitoplasty are rife with controversy. Malhotra, et at, 2018 summarized: Though many in the medical community support early genitoplasty, there are those who universally oppose all gender surgery on legal and ethical grounds. Opponents of early surgery focus on the principle of autonomy and the legal rights of the patient to make his or her decision regarding his or her body. On the other hand, in a casecontrol study of patients and parents involved in infant feminizing genitoplasty for CAH by Binet et al, 2016, nearly $90 \%$ of patients and $100 \%$ of parents support early surgery. Another retrospective study from Fagerholm et al., 2011 has shown that, despite some difficulties with sexual function, patients mostly preferred early surgery. Often, the decision for early clitoroplasty is driven by the parents and their desire for a "normal" appearance of the external genitalia.
This highlights the need for a multidisciplinary team that can offer not only the scientific rationale, but also the social support required to make the best decision for the child. ${ }^{25-}$ 27

\section{REFERENCES}

[1] Lee PA, Houk CP, Ahmed SF, Hughes IA, Achermann J, Ahmed F, et al. Consensus statement on management of intersex disorders. Pediatrics. 2006;118(2).

[2] Guerrero-Fernández J, Azcona San Julián C, Barreiro Conde J, Bermúdez de la Vega JA, Carcavilla Urquí A, Castaño González LA, et al. Management guidelines for disorders/different sex development (DSD). An Pediatría (English Ed. 2018;89(5):315.e1-315.e19.

[3] Agrawal SS, Chakraborty PP, Sinha A, Maiti A. Child with '46, XX' disorder of sex development: clues to diagnose aromatase deficiency. BMJ Case Rep. 2019;12(12):e232575.

[4] Lee PA, Nordenström A, Houk CP, Ahmed SF, Auchus $\mathrm{R}$, Baratz A, et al. Global disorders of sex development update since 2006: Perceptions, approach and care. Horm Res Paediatr. 2016;85(3):158-80.

[5] García-Acero M, Moreno O, Suárez F, Rojas A. Disorders of Sexual Development: Current Status and Progress in the Diagnostic Approach. Curr Urol. 2019;13(4):169-78.

[6] Ahmed SF, Rodie M. Investigation and initial management of ambiguous genitalia. Best Pract Res Clin Endocrinol Metab. Elsevier Ltd; 2010;24(2):197-218.

[7] Öcal G, Berberoğlu M, Sıklar Z, Aycan Z, Hacıhamdioglu B, Savas Erdeve Ş, et al. Clinical Review of 95 Patients with 46,XX Disorders of Sex Development Based on the New Chicago Classification. J Pediatr Adolesc Gynecol. 2015;28(1):6-11.

[8] Walia R, Singla M, Vaiphei K, Kumar S, Bhansali A. Disorders of sex development: a study of 194 cases. Endocr Connect. 2018;7(2):364-71.

[9] Öçal G. Current Concepts in Disorders of Sexual Development. journel Clin Res Pediatr Endocrinol. 2011;3(3):105-14.

[10] Douglas G, Axelrad ME, Brandt ML, Crabtree E, Dietrich JE, French S, et al. Consensus in Guidelines for Evaluation of DSD by the Texas Children's Hospital Multidisciplinary Gender Medicine Team. Int J Pediatr Endocrinol. 2010;2010:1-17.

[11] Lucas-Herald AK, Kyriakou A, Alimussina M, Guaragna-Filho G, Diver LA, McGowan R, et al. Serum Anti-Müllerian Hormone in the Prediction of Response to hCG Stimulation in Children With DSD. J Clin Endocrinol Metab. 2020;105(5):1608-16.

[12] Ahmed SF, Achermann JC, Arlt W, Balen A, Conway G, Edwards Z, et al. Society for Endocrinology UK guidance on the initial evaluation of an infant or an adolescent with a suspected disorder of sex development (Revised 2015). Clin Endocrinol (Oxf). 2016;84(5):771-88.

[13] Grant DB, Laurance BM, Atherden SM, Ryness J. HCG stimulation test in children with abnormal sexual development. Arch Dis Child. 1976;51(8):596-601. 
[14] Auchus RJ, Chang AY. 46,XX DSD: the masculinised female. Best Pract Res Clin Endocrinol Metab. Elsevier Ltd; 2010;24(2):219-42.

[15] Baronio, Ortolano, Menabò, Cassio, Baldazzi, Di Natale, et al. 46,XX DSD due to Androgen Excess in Monogenic Disorders of Steroidogenesis: Genetic Biochemical, and Clinical Features. Int J Mol Sci. 2019;20(18):4605.

[16] Belgorosky A, Guercio G, Pepe C, Saraco N, Rivarola MA. Genetic and Clinical Spectrum of Aromatase Deficiency in Infancy, Childhood and Adolescence. Horm Res Paediatr. 2009;72(6):321-30.

[17] Verma N, Jain V, Birla S, Jain R, Sharma A. Growth and hormonal profile from birth to adolescence of a girl with aromatase deficiency. J Pediatr Endocrinol Metab. 2012;25(11-12):1185-90.

[18] Bulun SE. Aromatase and estrogen receptor $\alpha$ deficiency. Fertil Steril. 2014;101(2):323-9.

[19] León NY, Reyes AP, Harley VR. A clinical algorithm to diagnose differences of sex development. Lancet Diabetes Endocrinol. 2019;7(7):560-74.

[20] Sandberg D, Gardner M, Cohen-Kettenis P. Psychological Aspects of the Treatment of Patients with Disorders of Sex Development. Semin Reprod Med. 2012;30(05):443-52.

[21] Kreukels BPC, Köhler B, Nordenström A, Roehle R, Thyen U, Bouvattier C, et al. Gender Dysphoria and Gender Change in Disorders of Sex Development/Intersex Conditions: Results From the dsd-LIFE Study. J Sex Med. 2018;15(5):777-85.
[22] Skordis N, Kyriakou A, Dror S, Mushailov A, Nicolaides NC. Gender dysphoria in children and adolescents: an overview. Hormones. 2020;19(3):267-76.

[23] Fisher AD, Ristori J, Fanni E, Castellini G, Forti G, Maggi M. Gender identity, gender assignment and reassignment in individuals with disorders of sex development: a major of dilemma. J Endocrinol Invest. Springer International Publishing; 2016;39(11):1207-24.

[24] Iezzi ML, Lasorella S, Varriale G, Zagaroli L, Ambrosi M, Verrotti A. Clitoromegaly in Childhood and Adolescence: Behind One Clinical Sign, a Clinical Sea. Sex Dev. 2018;12(4):163-74.

[25] Malhotra NR, Cheng EY. Reconstructive Therapy for Disorders of Sex Development. Encyclopedia of Reproduction. Second Edi. Elsevier; 2018. p. 444-53.

[26] Fagerholm R, Santtila P, Miettinen PI, Mattila A, Rintala R, Taskinen S. Sexual function and attitudes toward surgery after feminizing genitoplasty. J Urol. American Urological Association Education and Research, Inc.; 2011;185(5):1900-4.

[27] Binet A, Lardy H, Geslin D, Francois-Fiquet C, PoliMerol ML. Should we question early feminizing genitoplasty for patients with congenital adrenal hyperplasia and XX karyotype? J Pediatr Surg. Elsevier Inc.; 2016;51(3):465-8. 